\title{
Home Education Environment and Motivation as Correlates of Students' Academic Achievement in Physics in Nsukka Education Zone, Enugu State, Nigeria
}

\author{
Miriam Ifeyinwa Mamah ${ }^{1}$ Fidelis O. Nnadi ${ }^{2}$ Tochi Emmanuel Iwuagwu ${ }^{3 *}$ \\ 1.Department of Science Education, University of Nigeria, Nsukka, Enugu Nigeria \\ 2.Department of Science Education, Enugu State University of Science and Technology, Enugu Nigeria \\ 3.Department of Human Kinetics and Health Education, University of Nigeria, Nsukka, Enugu Nigeria
}

\begin{abstract}
In Nigeria, the growing rate of low enrollment and poor academic achievement of secondary school students in physics has become a source of concern to stakeholders in education. The study assessed home education environment and motivation as correlates of students' academic achievement in physics using correlational survey research design. A sample size of 333 SS2 physics students participated in the study. Home Education Environment and Motivation Questionnaire (HEEMQ) and Students' Physics Academic Achievement Spreadsheet (SPAAS) were used for data collection. Results reveal that $40 \%$ and $33 \%$ of the variation in students' academic achievement in physics is attributed to home education environment and motivation respectively. Home education environment and motivation significantly predicted students' academic achievement in physics. However, parents should create a favourable and conducive homeenvironment that can motivate their children to develop positive attitude towards learning physics and as well enhance their academic achievement in the subject.
\end{abstract}

Keywords: Home education environment, Motivation, Academic achievement, Physics, Correlate, Students

DOI: $10.7176 / \mathrm{JEP} / 12-23-06$

Publication date:August $31^{\text {st }} 2021$

\section{Introduction}

Physics is one of the core science subjects taught at the senior secondary school level in Nigeria. Physics is a natural science that has to do with the study of matter and its motion through space and time, along with related concepts, such as energy and force. The universe and its natural occurrences cannot be understood without a proper understanding of physics. The economic potential of developed nations rests directly on their innovations in science and technology which physics played the major role. Physics without a doubt is the pillar of technological and scientific development of most developed nations in the world. The applications of the theories, laws, and principles of physics are being applied in solving many problems of man on earth. Technologically, it has resulted in significant contributions to human comfort, societal survival, progress, and development. For instance, the concept of electromagnetism in nuclear physics has important scientific and technological applications. It is used in the production of televisions, computers, generators, and several household appliances which have significantly impacted the quality of life of the people and the economy of the society at large. According to Usman, Simyyap, and Fasanya (2019), many developed nations like the USA, Japan, France, China, and Russia attained their positions of world power as a result of their development in science and technology and physics played a key role in that direction. In agreement with this declaration, Okoroh (2003) posits that unless one understands the foundation of physics and links it with applied knowledge, one cannot call oneself an educated person in a country like Russia.

The study of physics opens up a broad way to many other disciplines (Astronomy, Geology, Chemistry, Biology, Engineering amongst others) that hold the key to scientific and technological development. According to Udoh (2012), studying physics offers students the opportunity to think critically, reason analytically,and acquire the spirit of inquiry. That is why the Nigerian Educational Research and Development Council (NERDC) (2009) stated in the new Nigeria senior secondary school physics curriculum that the objectives of physics in the secondary school curriculum are to: provide the basic literacy in physics for functional living in the society, acquire basic concepts and principles of physics as preparatory for further studies, acquire essential scientific skills and attitudes as a preparatory for technological application of physics, stimulate and enhance the creativity of students. The new secondary school physics curriculum in Nigeria, according to (Usman et al., 2019), is designed specifically to encourage all students to achieve their spiritual, intellectual and scientific potential as well as understand the relevance of learning physics in their daily lives.

However, in spite of the relevance of physics to the scientific and technological breakthrough of nations and these laudable objectives of physics, the subject has been faced with myriad of problems in Nigeria. Notwithstanding the concerted efforts being made by the state and federal governments, curriculum developers, science teachers, and other stakeholders towards making physics simple and easy for physics students, they still 
perceive physics to be a difficult course because of the abstract nature of physics just as mathematics, hence there is low enrolment and poor academic performance of students in physics (Akanbi, 2003; Olusola, Popoola, \& Omonijo, 2020; Omosewo, 1993; Nasiru, 2013; Semela, 2010).Physics educators and researchers have renewed the search for identifying and understanding the nature and scope of factors that influence learning and poor achievement of students in physics.Though, a number of factors contribute to that. It has also been discovered that certain factors can either influence or hinder the academic achievement of students at any level of education. Adegoke and Chukwunenye (2013) stressed that lack of functional physics laboratory and inadequate equipment for physics practical in most Nigerian secondary schools is hampering laboratory activities and these may be contributing to the low level of performance of students in physics.Ogunleye in Usman (2011) highlighted some factors prevailing against students' understanding and poor performance in secondary school physics to include; overloaded curriculum, uneven distribution of curriculum content, difficult nature of physics concepts and lack of competent physics teachers. Notable among the causes for low enrolment and poor achievement of students offering Physics in schools include: poor science and mathematics background of students at the junior secondary level of education, inadequate motivation of teachers, poor remuneration, inappropriate teaching strategiesemployed by the teachers, home education environment, insufficient number of qualified physics teachers and motivation (Chukwudi, 2013;Jegede and Adedayo, 2013; NERDC, 2009).Among these factors that contribute to low academic achievement of students in physics, home education environment and students' motivation need to be further investigated to order to identify the proportion/variation of change in students' academic achievement in physics that can be attributed to home education environment and motivation.

The education environment of the home is one of the environmental factors that play an important role in students' academic achievement. Nicole (2011) sees home education environment as the quality of human interactions, from the point of view of the child. The home education environment includes those aspects which foster growth and development of the students' intellectual ability, such as family trust and confidence, sharing of ideas, parents' support, parental approval, parental encouragement, care, affection, and approval and support of siblings. It is also referredto as the physical and psychological conditions that affect children (Ogbemudia \& Aiasa, 2013).Richter and Grieve (1991) have shown that the home environment and heredity work together in complex ways to determine a students' academic achievement. A conducive home environmentis very important forthe upbringing of children. It is a friendly, more egalitarian, andcomfortable environment. The effect of this kind of environment is that children learn not to be timid but to be challenged and they, therefore feel free to ask questions to satisfy their curiosity and thirst for knowledge. However, the reverse is the case in an unconducive environment.Children growing up in an unconducive environment may fail to develop their potentials and skills to the optimum extent, and this may have a negative effect on their performance in school and intelligence in social life, while children growing up in a conducive environment may show superior cognitive abilities and academic competence (McWayne, 2004).

Students' home education environment according to Obeta (2014) can either accelerate or hinder a student's academic performance. Furthermore, research carried out by Dzever (2015) showed that there is a positive and significant relationship between home environment and academic achievement. Sharma, Choudhary, and Sahdev (2013) reveal that there is a consistent relationship between home environment and students' academic achievement. Meanwhile, a study carried out by Song and John (2013) on home environment and academic achievement revealed that there is no significant relationship between home environment and students' academic achievement. This goes to show that there still exists a gap in the study of the relationship between home education environment and students' academic achievement. Gottfried, Fleming, and Gottfried (1998) also found that students whose homes had a greater emphasis on learning opportunities and activities were more academically intrinsically motivated to learn. The psychological environment of the home or the disciplinary pattern may mar or promotes excellence in students' academic achievement and the motivation to learn.

Motivation is seen as what initiates, drives, guides, and enhances or maintains goal-oriented behaviors. Bukhari, Hkan, Shahzadi, and Khalid(2014) referred to motivation as students' effort to enhance performance. According to Melissa (2018), motivation directs behaviour towards goals, it determines the specific goals towards which students strive for and affects the choices they make such as whether to enroll in an art class or science class. Lee and Brophy (1996) defined students' motivation in learning science as students' active engagement related to science tasks to achieve a better understanding of science. It is what drives students' actions towards learning a particular behaviour or achieving a particular academic goal. In other words, motivation is what directs students' actions or behaviours towards learning. Motivation could be intrinsic or extrinsic.

Intrinsic motivation is a motivation that is internal and is driven by interest or pleasure in the task itself and exists within the individual. It does not rely on external pressures or a desire for reward. According to Ryan and Deci (2000), intrinsic motivate is the self-desire to seek out new things and new challenges, to analyze one's capacity, to observe, and to gain knowledge. Intrinsic motivation has to do with the internal stimulus that spurs students to learn. Researchers often compare intrinsic motivation with extrinsic motivation, which is motivation 
governed by reinforcement contingencies. In extrinsic motivation, the stimulus to act is outside the individual. Alfred (2017) pointed out that extrinsic motivation involves rewards that occur outside the learners' control. These may include tokens of economic reward for good performance, threats of punishment that accompany undesirable behaviours, praise for good work among others. According to Shabeena, Nighat, Noshaba, and Sufiana (2013), extrinsic motivation techniques include grades, rewards, praise, punishment, and public recognition. Motivation is a multidimensional framework because people are usually motivated by a combination of different factors. Usually, educators consider intrinsic motivation to be more desirable and to result in better learning outcomes than extrinsic motivation (Deci, 2002).

A longitudinal study by Liu and Hou (2017) has shown that intrinsic motivation considerably promotes academic performance.A study carried out by Oriahi (2009) revealed that motivation generally has a high positive correlation in students' academic performance. Arbabisarjou, Zare, Shahrakipour, and Ghoreishinia (2016) found that there was a significant relationship between motivation and academic performance of students. Studies by (Amrai, Motlag, Zalani, \& Parhon, 2011; Awan, Noureen, Naz, 2011; Izuchi, Bruno, Onyekuru,2017) showed that motivation was significantly related to academic achievement. Although this evidence shows how motivation influences achievement, it is still a concern to know the proportion of variation in students' academic achievement that can be attributed to or predicted by motivation.

Based on the foregoing, the researchers observed that many researchers within and outside Nigeria believe that motivation and home education environment are potent predictors of academic achievement in any school subject. But none of the researchers investigated the influence of these variables on students' academic achievement in physics to see if possible improvement can be made on the trend of poor achievement in the subject as earlier mentioned.However, the assumption that the more conducive the environment is, the more motivated the students become, the higher the students' academic achievement, is questionable. This is because students whose home environment is poor and not conducive and who also lack parental support, encouragement, care, affection, and motivation have equally been found to develop their potentials and talents to the optimal level. They have also been found to have high academic achievement. From the foregoing, it can be seen that the effects of these variables (home environment and motivation) on students' academic achievement have not been extensively studied in order to draw a clear picture of the relationships among these variables. Thus there is a need to investigate these variables collectively in order to objectively establish the proportion of variation in students' academic achievement in physics that can be attributed to or predicted by home education environment and motivation. The main purpose of this study was to determine the extent to which home education environment and motivation predict students' academic achievement in physics. Specifically, the study assessed the proportion of variation in students' academic achievement in physics that can be attributed to or predicted by home education environment and motivation.

The regression model obtained from the study serve as a theoretical model for predicting physics achievement based on the knowledge of home education environment and motivation. That means with this model, one can predict a student's academic achievement given values of home education environment and motivation. Teachers' knowledge of this variables and how it relates to students' academic achievement would enable them to restructure their teaching methods and instructional resources to meet students from different home environment in order to carry every student along during teaching and learning bearing in mind that students come from different home environmental background. It would also help parents with low socioeconomic status to intensify their efforts towards providing their children with relevant learning materials and conducive learning environment at home to enhance the students' academic achievement and motivation to learn.

\subsection{Materials and Methods}

\section{Study setting and design}

This study adopted a correlational survey research design. The study was conducted in Nsukka Education Zone of Enugu State, Nigeria. The Zone comprises of three local government areas (LGAs) namely: Nsukka LGA, Igbo-Etiti LGA and Uzo-Uwani LGA.

\section{Study population and sampling design}

The population consisted of 2,520 SS2 physics students in all the 56 government-owned senior secondary schools in the Zone (Source: Post Primary Management Board Enugu State, 2018).

A sample of 333 SS2 physics students was used for this study. A multi-stage sampling procedure was adopted for this study. In the first stage, two local government areas (Nsukka and Igbo-Etiti) were selected from the three local government areas using simple random sampling technique with replacement. The names of the local governments were written on a piece of paper, folded and put in a container, shuffled and the researcher drew the local government areas with replacement (i.e. balloting with replacement). At the second stage, eight (8) secondary schools were selected from Nsukka local government and four (4) secondary schools were selected from Igbo-Etiti local government area using proportionate stratified sampling technique. In the third stage, 
proportionate stratified sampling technique was also used to sample two hundred and thirteen physics students (213) and one hundred and twenty (120) physics students from Nsukka and Igbo-Etiti LGAs respectively using the formula (Number of students in a local government divided by the total number of students in the two local government areas times the sample size. i.e. $\mathrm{n} \div \mathrm{N}$ x sample size, where $\mathrm{n}=$ the number of students in a local government while $\mathrm{N}=$ total number of students in the two local government areas). Since the two local government areas were not equal, proportionate stratified sampling technique was used in the third stage.

Data collection tools and procedure

Two instruments were used for data collection [questionnaire titled "Home Education Environment and Motivation Questionnaire" (HEEMQ) and Students' Physics Academic Achievement Spreadsheet (SPAAS)] which was used to collect the existing three consecutive ends of term's examination results of the sampled students. The questionnaire was grouped into two parts. Part A sought information on students' demographic data, such as student identification number, school name, and students' class.Part B consisted of two clusters (I and II). Cluster I consisted of 15 items relating to home education environment while Cluster II consisted of 15 items relating to motivation. The questionnaire has a total of 30 items modeled on a 4-point rating scale. The response options for the items in HEEMQ were - Always (Al); Sometimes (S); Rarely (R) and Never (N) with numerical values of 4, 32 , and 1 points assigned to each of the responses respectively.

The instruments (HEEMQ and SPAAS) were Face Validated by one expert in Educational Psychology, Department of Educational Foundations, and two experts in Measurement and Evaluation in the Department of Science Education all atthe University of Nigeria, Nsukka. The reliability of the modified instrument (HEEMQ) after face validation was ascertained through trial-testing of the instrument using a similar sample of students from other schools in a neighbouring Education Zone that was not part of the sampled Zone of this study. Thirty (30) students were used for trial testing. The reason for trial-testing was to determine the internal consistency of the items. Cronbach's alpha was used and the reliability coefficients of 0.77 and 0.83 were obtained for clusters I and II of the questionnaire with an overall estimate of 0.81 .

\section{Data analysis}

Pearson's productmoment correlation coefficient, as well as the coefficient of determination $\left(\mathrm{R}^{2}\right)$ and the regression model/equation, were used to analyze the data. All the null hypotheses were tested using the regression ANOVA F-statistic at 0.05 level of significance. Specifically, the F-test and t-test were used to test for the significance of the regression coefficient and the regression model. A correlation coefficient of 0.00 was regarded as no relationship, 0.01 to 0.29 was regarded as a low relationship, 0.30 to 0.79 was regarded as a moderate relationship and correlation coefficient of 0.80 and above was regarded asa high relationship (Dowine \& Heath, 1974 as cited in Nworgu, 2015).

\subsubsection{Results}

Table 1: Pearson's product moment correlation analysis of the proportion of students' academic achievement in physics that is predicted by home education environment

\begin{tabular}{lccccc}
\hline Variable & $\overline{\boldsymbol{X}}$ & SD & N & $\mathbf{R}$ & $\mathbf{R}^{2}$ \\
\hline Home Education Environment & 64.35 & 17.15 & 333 & 0.63 & 0.40 \\
Students' Achievement & 70.68 & 14.14 & & & \\
\hline
\end{tabular}
$\alpha=0.05, \mathrm{R}^{2}=$ coefficient of determination

The result shows that the correlation coefficient obtained was 0.63 . This means that there exists a moderate positive relationship between home education environment and students' academic achievement in physics. Table 1 also shows that the coefficient of determination $\left(\mathrm{R}^{2}\right)$ associated with the correlation coefficient of 0.63 was 0.40 . This coefficient of determination $\left(\mathrm{R}^{2}\right)$ also indicates that $40 \%$ is the proportion of variation in students' academic achievement in physics is attributed to or predicted by home education environment.

Table 2: Pearson's product moment correlation analysis of the proportion of students' academic achievement in physics that is predicted by motivation

\begin{tabular}{lccccc}
\hline Variable & $\overline{\boldsymbol{X}}$ & SD & N & R & $\mathbf{R}^{2}$ \\
\hline Motivation & 54.27 & 13.48 & 333 & 0.58 & 0.33 \\
Students' Achievement & 70.68 & 14.14 & & & \\
\hline
\end{tabular}

$\alpha=0.05, \mathrm{R}^{2}=$ coefficient of determination

The result shows that the correlation coefficient obtained was 0.58 . This means that there exists a direct positive relationship between motivation and students' academic achievement in physics. Table 2 also shows that the coefficient of determination $\left(\mathrm{R}^{2}\right)$ associated with the correlation coefficient of 0.58 was 0.33 . This coefficient of determination $\left(\mathrm{R}^{2}\right)$ indicates that $33 \%$ of the variation in students' academic achievement in physics is attributed to or predicted by motivation. 
Table 3a: Regression Model

\begin{tabular}{|c|c|c|c|c|c|}
\hline \multirow[t]{2}{*}{ Model Variables } & \multicolumn{2}{|c|}{ Unstandardized Coefficients } & \multirow{2}{*}{$\begin{array}{l}\text { Standardized } \\
\text { Coefficients } \\
\text { Beta }\end{array}$} & \multirow[t]{2}{*}{$\mathbf{t}$} & \multirow[t]{2}{*}{ Sig. } \\
\hline & $\mathbf{B}$ & Std. Erro & & & \\
\hline 1 (constant) & 16.45 & 2.51 & & 6.54 & 0.00 \\
\hline Home education environment & 0.58 & 0.03 & 0.43 & 14.78 & 0.00 \\
\hline Motivation & 0.42 & 0.04 & 0.36 & 12.84 & 0.00 \\
\hline
\end{tabular}

Dependent Variable: Students' Academic Achievement in Physics (SAA)

Table 3b: Model Summary

\begin{tabular}{cllcc}
\hline Model & R & R square & Adjusted R Square & Std. Error of the Estimate \\
\hline 1 & 0.77 & 0.60 & 0.59 & 9.00 \\
\hline
\end{tabular}

1. Predictors: (Constant), Home Education Environment (HEE), Motivation (M)

From Table $3 \mathrm{a}$, the regression model in raw score form is:

$\mathrm{SAA}=0.58 \mathrm{HEE}+0.42 \mathrm{M}+16.45$ while the regression model in standard score form is $Z_{\mathrm{SAA}}=0.43 Z_{\mathrm{HEE}}+$ $0.36_{\mathrm{M}}$. From the regression model, the two predictor variables proved potent at predicting students' academic achievement in physics to an appreciable extent with the home environment having the highest predictive capacity followed by motivation. The regression model shows that one unit change in home education environment will produce 0.58 change in students' academic achievement in physics and also one unit change in motivation will produce 0.42 change in students' academic achievement in physics while 16.45 is the level of students' academic achievement without the influence of the predictor variables, that is, home education environment and motivation. The result in Table $3 \mathrm{~b}$ seeks to find out how much of the overall variance of students' academic achievement in physics is predicted by the two predictor variables in the study. The result shows that the relationship between the predictor variables and the criterion variable (i.e. students' academic achievement) was 0.77 and the coefficient of determination ( $R$ Square) was 0.60 . This means that the model as a whole explained $60 \%$ of the total variance of students' academic achievement in physics. This also means that $60 \%$ of students' academic achievement is predicted or accounted for by the predictor variables - home education environment and motivation

Table 4: ANOVA F-test for the significance of regression: home education environment and students' academic achievement in physics

\begin{tabular}{lccccc}
\hline Model & Sum of Squares & Df & Mean Square & F & Sig. \\
\hline Regression & 26267.421 & 1 & 26267.421 & 216.613 & .000 \\
Residual & 40138.471 & 331 & 121.264 & & \\
Total & 66405.892 & 332 & & & \\
\hline \multicolumn{1}{c}{$\quad \alpha=0.05$} & & & &
\end{tabular}

The result in Table 4 shows that an F-ratio of 216.613 with an associated exact probability value of 0.00 was obtained. This probability value of 0.00 was compared with 0.05 set as the level of significance for testing the hypothesis and it was found to be significant because 0.00 is less than 0.05 . The null hypothesis which stated that; home education environment does not significantly predict students' academic achievement in physics was therefore rejected. The inference drawn was that home education environment significantly predicts students' academic achievement in physics. In other words, home education environment is a good predictor of students' academic achievement.

Table 5: ANOVA F-test for the significance of regression: Motivation and students' academic achievement in physics

\begin{tabular}{lrrrrr}
\hline Model & Sum of Squares & Df & Mean Square & \multicolumn{1}{c}{ F } & Sig. \\
\hline Regression & 21953.507 & 1 & 21953.507 & 163.470 & .000 \\
Residual & 44452.385 & 331 & 134.297 & & \\
Total $\quad \alpha=0.05$ & 66405.892 & 332 & & & \\
\hline \multicolumn{1}{c}{$\alpha=0.07$}
\end{tabular}

The result in Table 5 shows that an F-ratio of 163.470 with an associated exact probability value of 0.00 was obtained. This probability value of 0.00 was compared with 0.05 set as the level of significance for testing the hypothesis and it was found to be significant because 0.00 is less than 0.05 . The null hypothesis which stated that; motivation does not significantly predict students' academic achievement in physics was therefore rejected. The inference drawn was that motivation significantly predicts students' academic achievement in physics. In other words, motivation is a good predictor of students' academic achievement. 


\subsubsection{Discussion}

The finding of the study showed that there exists a moderate and positive relationship between home education environment and students' academic achievement in physics. The result also showed that $40 \%$ of students' academic achievement in physics is predicted by home education environment. Besides, the corresponding hypotheses showed that home education environment significantly predicted students' academic achievement in physics. This finding is consistent with the earlier findings by Dzever (2015) who found that there is a positive and significant relationship between home environment and academic achievement. Similarly, Oommen (2015) found a significant correlation between home environment and academic achievement among higher secondary school students. In the same way, Sharma et al. (2013) found that there is a consistent relationship between home environment and students' academic achievement. Supporting this, Biedinger(2011) found that the home environment is an important predictor of cognitive abilities. Gottfried et al. (1998) also found that students whose homes hada greater emphasis on learning opportunities and activities were more academically intrinsically motivated to learn. This indicates that the home education environment of the student influences their academic achievement positively or negatively. This result confirmed the significance of having educational and developmental materials at home. It also demonstrated the importance of parents reading, playing and discussing with their children at home so as to create an enabling environment that is conducive enough to motivate their children towards learning.

The finding of the study also showed that there exists a moderate and positive relationship between motivation and students' academic achievement in physics. The result showed that $33 \%$ of students' academic achievement in physics is predicted by motivation. It also revealed that motivation significantly predicted students' academic achievement in physics. This implies that when students are adequately motivated, theytend to achieve better academically. This result is in agreement with earlier findings bya study carried out by Oriahi (2009) who found that motivation generally has a high positive correlation with students' academic performance. Also, Arbabisarjou et al. (2016) found that there was a significant relationship between motivation and academic performance of students. Izuchi et al. (2017) also found that motivation was significantly related to academic achievement. This showed that the more students are being motivated, the better their academic achievement.

The finding of this study also showed that the regression model in raw score form is SAA $=0.58 \mathrm{HEE}+$ $0.42 \mathrm{M}+16.45$ while the regression model in standard score form is $Z_{\mathrm{SAA}}=0.43 Z_{\mathrm{HEE}}+0.36_{\mathrm{M}}$. From the regression model, the two predictor variables proved potent at predicting students' academic achievement in physics to an appreciable extent with home environment having the highest predictive capacity followed by motivation. The regression model shows that one unit change in home education environment and motivation will produce 0.58 and 0.42 change in students' academic achievement in physics respectively. The result also showed that the model as a whole explained $60 \%$ of the total variance of students' academic achievement in physics. This means that $60 \%$ of students' academic achievement is predicted or can be accounted for by the predictor variables - home education environment and motivation. This implies thatstudents are more likely to achieve higher or learn better when the education environment of the home is conducive and whenthey are adequately motivated.

The study revealed that home education environment and motivation are powerfulpredictors of students' academic achievement in physics. This implies that parents ought to create a favourable and conducive homeenvironment that will enable their children/wards to develop theright attitude towards physics and be well motivated so as to improve their achievement in the subjector else their achievement in physics will be negativelyaffected. They should also establish and maintain a good home environment where love, hardworking and excellence are encouraged in order to bring out the children's best academic performance. The findings of this study also have implications for teachers. Students vary in their ability and attitude towards learning; teachers should therefore recognize this and attend to their students as an individual. Teachers ought to take the influence of these variablesinto consideration during teaching and learning processes. They need to adoptstrategies or methods that will encourage students toparticipate actively in class in order to perform well academically.

\subsubsection{Conclusions and Recommendations}

Our study showed that home education environment and motivation significantly predicted students' academic achievement in physics. The regression model therefore, provides information required by teachers and other stakeholders in education in understanding the influence of home education environment and motivation on students' academic achievement in physics and thereby providing a real opportunity for the use of this information in predicting students' achievement in physics. It gives stakeholders the opportunity to comprehend and to be in a position to help improve students' academic achievement in physics.However, parents should create a favourable and conducive homeenvironment that can motivate their children to develop positive attitude towards learning physics and as well enhance their academic achievement in the subject.Parents should take part in the education of their children at home in order to enhance the educational environment of the home as well.Parents should therefore provide adequate funds for their children while in school. This will help in providing the necessary reading materials that may enhance theirkeenness for academic activities in all subjects 
and promote their academic achievement. Teachers also should adopt some teaching strategies and use instructional materialsthat will bring out students' inquisitiveness and enhancetheir academic motivation.

\section{References}

Adegoke, B. A., \& Chukwunenye,N. (2013). Improving students' learning outcomes in practical physics, which is better? Computer simulated experiment or hands-on experiment? IOSR Journal of Research \& Method in Education (IOSR-JRME), 2(6),18-26.

Akanbi, A. O. (2003).Trend in physics education in secondary school in Kwara State. Lafiagi Journal ofScience Education, 5(1\&2), 69-75.

Alfred, P. (2017). Nine strategies for motivating students in mathematics. Available at https://edutopia.org/blog/9-strategies (accessed 12 February, 2020)

Amrai, K, Motlag, S. E., Zalani, H. A., \& Parhon, H. (2011). The relationship between academic motivation and academic achievement students. Procedia - Social and Behavioral Sciences, 15, 399-402.

Arbabisarjou, A., Zare, S., Shahrakipour, M., \& Ghoreishinia, G. (2016). The relationship between academic achievement motivation and academic performance among medical students. International Journal of Pharmacy \& Technolog, 8(2), 12272-12280.

Awan, R. U., Noureen, G., \& Naz, A. (2011). A study of relationship between achievement motivation, selfconcept and achievement in English and Mathematics at Secondary Level. International Education Studies, 4(3), $72-79$.

Biedinger, N. (2011).The influence of education and home environment on the cognitive outcomes of preschool children in Germany. Hindawi Publishing CorporationChild Development Research. http://doi:10.1155/2011/916303

Bukhari, T. Z., Khan, J., Shahzadi, I., \&Khalid, A. (2014). Mediating role of motivation to learn in determining e-learning outcomes: a conceptual study. Business and Management,6(2), 179-189.

Chukwudi, O. C. (2013). Academic Performance of Secondary School Students: The effect of home environment. Double Gist Publishers. Nig.

Deci, E. L. (2002). The "what" and "why"of goal pursuits: Human needs and the self-determination of behavior. Psychological Inquiry, 11(1), 227-268.

Dzever, L. T. (2015). The impact of home environment factors on academic performance of senior secondary school students in Garki Area District, Abuja -Nigeria. Bulgarian Journal of Science and Education Policy (BJSEP,)9,1.

Gottfried, A., Fleming, J., \& Gottfried, A. (1998). Role of cognitively stimulating home environment in children's academic intrinsic motivation: A longitudinal study. Child Development,69(5), 1448 - 1460.

Izuchi, M. R. N., Bruno, U., \& Onyekuru, B. U. (2017). Relationships among academic self-concept, academic motivation and academic achievement among college students. European Journal of Research and Reflection in Educational Sciences, 5(2), 93 - 102.

Jegede, S. A., \& Adedayo, J. O. (2013). Enriching physics education in Nigeria towards enhancing a sustainable technological development. Greener Journal of Educational,3(2), 080-084.

Lee, O.,\& Brophy, J. (1996). Motivational patterns observed in sixth-grade science classrooms. Journal of Research in Science Teaching,33(3), 585-610.

Liu, Y.,\&Hou, S. (2017).Potential reciprocal relationship between motivation and achievement: A longitudinal study. Social Psychological International. http://doi.org/10.1177/0143034317710574

McWayne, C. (2004). A multivariate examination of parent involvement and the social and academic competencies of urban kindergarten children. Psychology in the Schools, 41(1), 363-375.

Mellissa, H. (2018).The importance of motivation in an educational environment. Available at https://study.com/academy/lesson (accessed 4 July 2020)

Nasiru, S. (2013). Tackling poor performance in public examinations: A collective fight.Available athttp://ngex.com/news/public article.php/ (accessed 4 July 2020)

Nicole, B. (2011). The influence of education and home environment on the cognitive outcomes of preschool children in Germany. Child Development Research, 201, 110 -119.

Nigerian Educational Research and Development Council (NERDC). (2009).National policy on education 5th edition. Lagos: NERDC Press. Available at https://study.com/academy/lesson (accessed 4 July 2020)

Nworgu, B. G. (2015).Educational research: Basic issues and methodology (3rd ed.). Nsukka: University Trust Publishers.

Obeta, A. O. (2014). Home environmental factors affecting students' academic performance in Abia State, Nigeria. Rura Environment. Education. Personality Jelgava, 7.

Ogbemudia M. I., \& Aiasa M. V. (2013). Influence of home environment on the academic performance of primary five pupils' in English Language in Orhionmwon Local Government Area of Edo State. Merit Research Journal of Education and Review, 1(5), 120-125 
Okoroh, D. (2003)Physics technology and society: The journey so far. Science Teachers Association of Nigeria. 44 ${ }^{\text {th }}$ Annual Conference Proceedings. Ibadan: Heinemann Education Books Plc.

Olusola, O. O., Popoola, O. E., \& Omonijo, A. R. (2020).Comparative analysis and gender effects of students' academic performance in senior secondary school certificate examination in physics between year 2013 and 2017 in Ekiti State. European Journal of Educational and Development Psychology,8(1), 11-19,

Omosewo, E. O. (1993). A survey of the physics enrolment pattern in senior secondary schools of Kwara State. Ife Journal of Education Studies, 6(1), 141-150.

Oommen, N. M. (2015). Home environment and academic achievement of students at higher secondary level.International Journal of Current Research, 7(7), 18745-18747.

Oriahi, C. I. (2009). Influence of motivation on students' academic performance. Journal of the Social Sciences, 4(1), 30-3.

Post-primary Management Board Enugu State. (2018)Secondary school students population. Enugu: Statistics Division.

Richter, L. M., \& Grieve, K. W. (1991). Home environment and cognitive development of black infants in impoverished South African families. Infant Mental Health Journal,12(2), 88-102.

Ryan, R. M., \& Deci, E. L. (2000). Self-determination theory and the facilitation of intrinsic motivation, social development, and well-being. American Psychologist,55(1), 68-7.

Semela, T. (2010). Who is joining physics and why? Factors influencing the choice of physics students among Ethiopian University. International Journal of Environmental and Science, 5, 319-340.

Shabeena, S., Nighat, P., Noshaba, \& Sufiana, K. M. (2013).Motivational techniques for effective learning: A meta-analysis. The author.

Sharma, R., Choudhary, A., \& Sahdev, S. (2013).Effect of home environment on academic achievement of 11 th class students. Indian Streams Research Journal,3(5), 2230-7850.

Song, I., \& John, H. (2013). Home environment, self-concept, and academic achievement: A causal modeling approach. Journal of Educational Psychology, 76(6), 1269-1281.

Udoh, A. U. (2012). Refocusing Physics Education in Nigeria: Issues and Challenges in Teacher Education.Mediterranean Journal of Social Sciences, 3(13), 11-19.

Usman, I. S. (2011). Educational reforms and physics education in Nigeria: An overview of areas of needs in physics education. UMMYU Journal of Educational Research,3(1), 1-9.

Usman, I. S., Simyyap, W. L., \& Fasanya, A. G. (2019). Challenges of effective implementation of new secondary school physics curriculum in public and private schools in Nigeria. Journal of Science Technology and Education, 7(3), 2277-0011. 